\title{
Preparing for SMOS: Sea Salinity Campaigns and Results
}

\author{
Søbjærg, Sten Schmidl; Balling, Jan E.; Kristensen, Steen Savstrup; Skou, Niels
}

Published in:

Proceedings of IGARSS'06

Link to article, DOI:

10.1109/IGARSS.2006.438

Publication date:

2006

Document Version

Publisher's PDF, also known as Version of record

Link back to DTU Orbit

Citation (APA):

Søbjærg, S. S., Balling, J. E., Kristensen, S. S., \& Skou, N. (2006). Preparing for SMOS: Sea Salinity Campaigns and Results. In Proceedings of IGARSS'06 IEEE. https://doi.org/10.1109/IGARSS.2006.438

\section{General rights}

Copyright and moral rights for the publications made accessible in the public portal are retained by the authors and/or other copyright owners and it is a condition of accessing publications that users recognise and abide by the legal requirements associated with these rights.

- Users may download and print one copy of any publication from the public portal for the purpose of private study or research.

- You may not further distribute the material or use it for any profit-making activity or commercial gain

- You may freely distribute the URL identifying the publication in the public portal 


\title{
Preparing for SMOS: Sea Salinity Campaigns and Results
}

\author{
Sten S. Søbjærg, Jan Balling, Steen S. Kristensen, and Niels Skou \\ Ørsted-DTU, B 348 \\ Technical University of Denmark \\ DK 2800 Lyngby, Denmark \\ sss@oersted.dtu.dk
}

\begin{abstract}
Mapping of sea surface salinity, based on L-band radiometric measurements, is presently investigated as a preparation for space missions. Special concern is on correction for effects caused by the sea surface roughness, and this paper will address two campaigns, LOSAC and CoSMOS, with the aim of investigating these effects. Conclusions from LOSAC are presented, and open issues to be investigated during the presently ongoing CoSMOS campaign are outlined. Finally, the installation and campaign plan for CoSMOS are presented.
\end{abstract}

Keywords; microwave, radiometer, sea salinity, campaign

\section{INTRODUCTION}

Sea surface salinity, SSS, remote sensing, especially by Lband radiometry, is presently an important issue as both ESA and NASA are preparing satellite missions for that purpose. ESA will launch its synthetic aperture radiometer, SMOS in September 2007, while NASA plans to launch its Aquarius push-broom radiometer in 2008.

An L-band radiometer can measure sea salinity. But the brightness temperature, as seen by the radiometer, depends also on the sea surface temperature and roughness (often expressed through the wind speed), and of atmospheric and ionospheric propagation properties. The measurements can be disturbed by interference from external active services (RFI) as well as space radiation. And finally, instrument stability and calibration are important issues.

The sea surface temperature is well measured by existing sensors. The atmospheric and ionospheric propagation issues have been carefully scrutinized, and it is believed that the effect on the received brightness temperature can be corrected for. Instruments of the required stability and calibration fidelity can be designed and built, and moreover methods like vicarious calibration for correction of residual calibration drifts have been devised. Open issues are thus the effect of the sea surface roughness and a survey of possible sources of external interference.

\section{THE LOSAC CAMPAIGN}

The first airborne campaign to address the possible sea surface roughness effects was the LOSAC, L-band Ocean Salinity Airborne Campaign, with primary target area in the North Sea. The fully polarimetric EMIRAD L-band airborne radiometer, measuring the full Stokes vector simultaneously, was used throughout the campaign, and a complete description of the instrument can be found in [1]. The integration time of the instrument is programmable in steps of $8 \mathrm{msec}$., but in the LOSAC the integration time was kept around 1 sec., resulting in a $\Delta \mathrm{T}$ of the radiometer less than $50 \mathrm{mK}$. Likewise, all flight operations were carried out after sunset in order to avoid possible Sun reflections.

The LOSAC campaign was originally focused on possible azimuth signatures caused by the wind, and hence the primary flight pattern was a circle-like pattern, letting the aircraft drift with the wind in order to minimize attitude variations over the circles. Many circle flights were carried out, covering wind speeds from almost $0 \mathrm{~m} / \mathrm{sec}$. to $20 \mathrm{~m} / \mathrm{sec}$., but also level flight patterns, sampling eight different azimuth angles within 30 minutes, were carried out in order to improve integration time. The two flights patterns are shown in figure 1 and a description of the campaign can be found in [2].
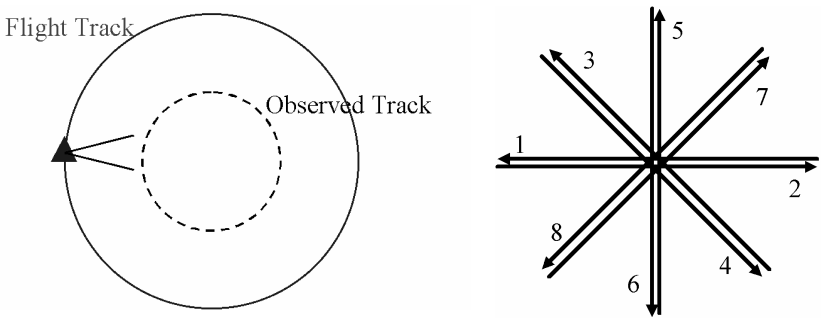

Figure 1. LOSAC Flight patterns

A typical result from a single circle track shows variations in all Stokes parameters of several Kelvin. The vertical polarization as well as the $3^{\text {rd }}$ Stokes parameter typically have variations of $1.5 \mathrm{~K}$ from peak to peak, while the horizontal polarization can have up to $4 \mathrm{~K}$. The $4^{\text {th }}$ Stokes parameter normally stays within $\pm 0.3 \mathrm{~K}$ over a full circle. Results from several subsequent circles show, that signatures are typically not repeated from pass to pass, and with the radiometric sensitivity being $50 \mathrm{mK}$, a first conclusion from the LOSAC is thus, that some source of geophysical noise is present in the signals.

The flight altitude was typically $6000 \mathrm{ft}$., equal to a footprint of $800 \mathrm{~m}$ by $1000 \mathrm{~m}$, using a $1 \mathrm{~m}$ aperture square shaped horn antenna, installed side-looking at a $23^{\circ}$ depression angle. Alternative altitudes, up to $9000 \mathrm{ft}$., were used during the

The described work was supported by the European Space Agency 
campaign, but for all selections of foot-print size, the ocean surface is not completely homegeneous within the observed area, and similar amount of geophysical noise is observed, probably due to wave and swell features being partly resolved by the foot-print.

If the geophysical noise is expected random, it is easily reduced through averaging - in space or in time - provided that samples can be considered statistically independent. Obviously the change of spatial integration through the change of flight altitude did not provide enough statistically independent information, and as no higher altitude was possible due to the aircraft and installation limitations, integration in time was considered. One way of implementation is through acquisition of many circles, which are then integrated with respect to azimuth observation direction. As each circles takes between two and five minutes dependent on the aircraft bank angle, independent observations can be assumed. For a flight in medium wind, $10 \mathrm{~m} / \mathrm{sec}$., the pattern in figure 2 was achiwed, after integration of 16 independent circles.
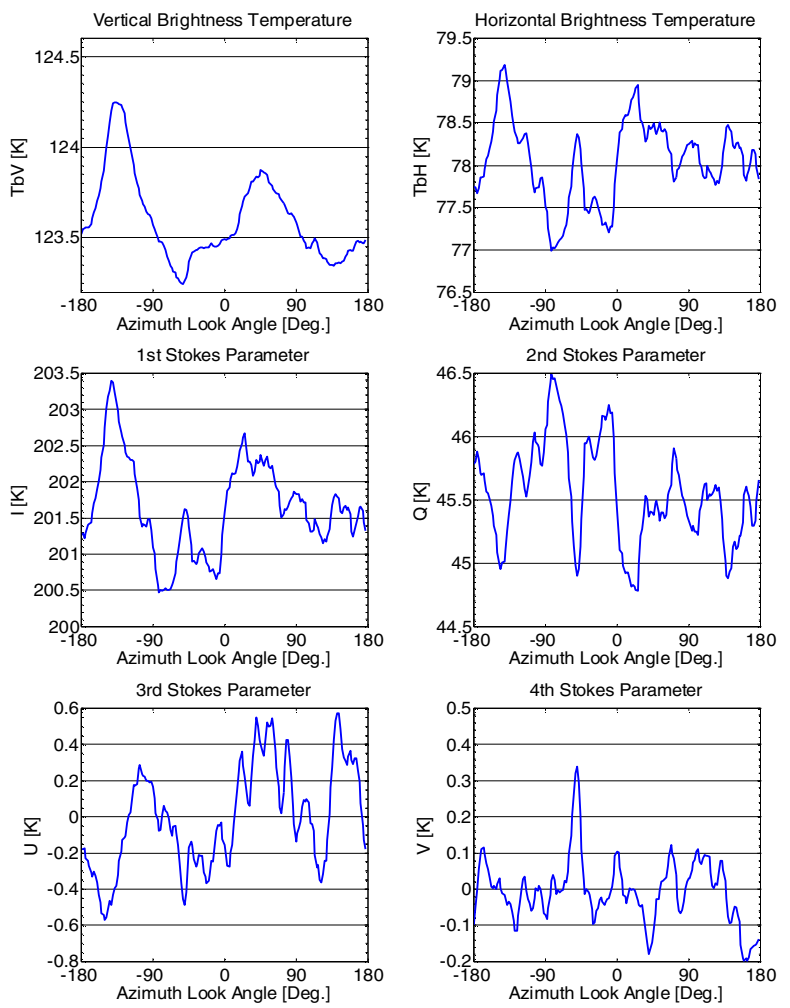

Figure 2. Circle signature for $10 \mathrm{~m} / \mathrm{sec}$. wind speed, observing the sea surface at $45^{\circ}$ incidence angle. 16 individual circles are averaged.

An alternative way of integration is through sampling of a finite number of azimuth directions, equal to the right part of figure 1, but tracks must be long enough to filter out slow variations (typically with periods of $30 \mathrm{sec}$. to 1 minute) in parameters such as surface wave pattern and wind speed. As a comprimise, tracks of at least 2 minutes were acquired. A leastsquare $1^{\text {st }}$ and $2^{\text {nd }}$ order harmonic fit was estimated from the eight tracks, and a signature similar to figure 2 was obtained.

\section{GALACTIC BACKGROUND CORRECTIONS}

For all signatures it is obvious, that a signal is present, and as the flights are carried out at night, the most likely source is identified as the galaxy being reflected in the sea surface. Space radiation (including the effect of the Sun and the Moon) is in itself well mapped, and assuming a simple reflection at the sea surface, the galactic contribution is easily calculated. The pointing direction is found from the installation properties and the aircraft attitude, and the down-welling radiation is directly found from a sky map look-up.

The reflection coefficient can be found theoretically by subtracting the measured emissivity from 1, but generally this method will subtract a too high value, providing a resulting signature with negative peaks, compared to figure 2. An alternative method is to calculate the regression coefficient between the Stokes parameters and the downwelling radiation, and thus remove completely the azimuth signature dependence on the background radiation. Figure 3 shows this method applied to the vertical polarization of the signature in figure 2, with the downwelling radiation shown at an arbitrary offset for comparison.

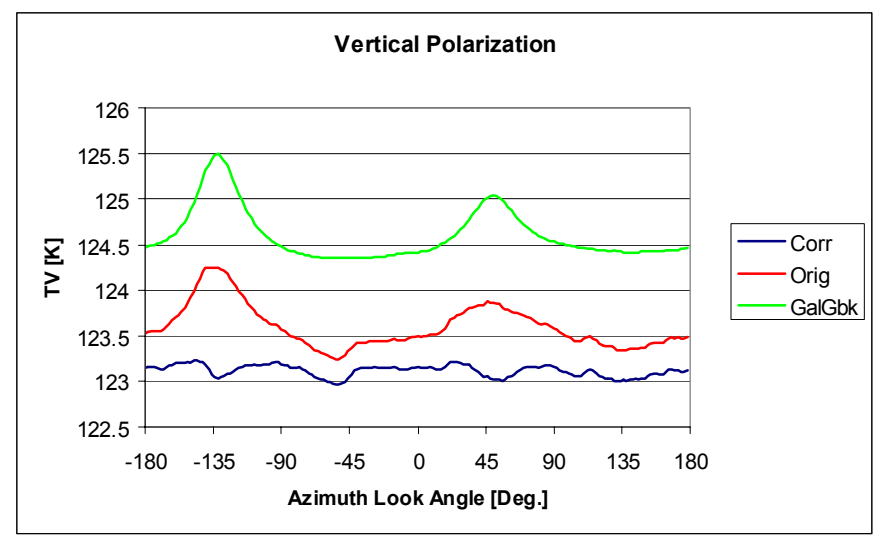

Figure 3. Circle signature for vertical polarization for $10 \mathrm{~m} / \mathrm{sec}$. wind speed. The red curve is the measured data, the green curve the down-welling galactic radiation offset arbitrarily, and the blue curve is the result after correction.

As indicated by the figure, the correlation between the down-welling radiation and the measured data is significant, but the assumption of simple reflection tends to result in overcorrected points at the maximum points of the galactic radiation, while points at the edges exhibit small undercorrected peaks. For horizontal polarization the same method is applied, but due to the larger geophysical noise, the correlation is less obvious.

Corrections have been applied to all LOSAC flights and both polarizations, and as expected, the resulting regression coefficient always turned out to be smaller than the Fresnel reflection coefficient. However, results ranging from 0.3 times the Fresnel coefficient to 0.9 times the Fresnel coefficient were found, and no obvious correlation to the wind speed was encountered. This indicates a more complex reflection mechanism as a function of the surface roughness. This is often taken to be a direct function of wind speed, but as indicated above, this is not necessarily true. 
The typical circle signature after removal of galactic background radiation appears very flat over the whole azimuth range, and figure 4 shows the result after correction of the measurements, shown in figure 2.
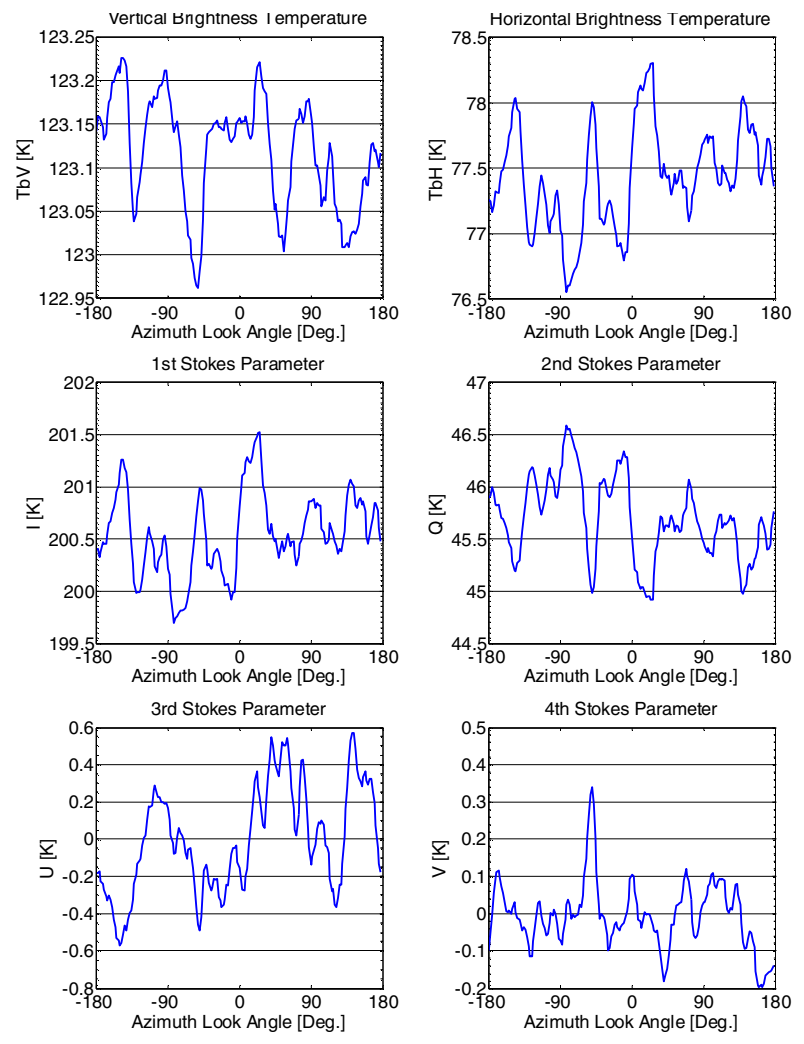

Figure 4. Circle signature for $10 \mathrm{~m} / \mathrm{sec}$. wind speed, at $45^{\circ}$ incidence angle.

16 circles are averaged, and galactic background radiation is removed

The total signal, present in each polarization, can be calculated as a root-mean-square value over the full azimuth range, and for integration of $\mathrm{N}$ circles, this value is reduced by approximately the square-root of $\mathrm{N}$, according to integration of independent observations. No systematic deviation from this integration gain is seen, even for integration of all 16 circles, and the remaining signals for the above shown signature are:

$$
\begin{aligned}
& \alpha\left[\mathrm{T}_{\text {vertical }}\right]=64 \mathrm{mK} \\
& \alpha\left[\mathrm{T}_{\text {horizontal }}\right]=389 \mathrm{mK} \\
& \alpha\left[\mathrm{T}_{\text {3rd Stokes Parameter }}\right]=285 \mathrm{mK} \\
& \alpha\left[\mathrm{T}_{\text {th Stokes Parameter }}\right]=90 \mathrm{mK}
\end{aligned}
$$

Based on LOSAC, an azimuth signature as a function of the wind speed can not be proven. Signals up to $200 \mathrm{mK}$ peak-peak may be hidden in the geophysical noise, and due to the limited number of circles, 16, signals of this order of magnitude will not be detectable in the integration statistics. Harmonic analysis and identification of possible $1^{\text {st }}$ and $2^{\text {nd }}$ order harmonics in the LOSAC data, as expected at higher frequencies as wind driven signals, provide very similar conclusions. No signatures larger than typically $100 \mathrm{mK}$ are found, and phases with respect to the wind direction are random. Harmonic fits from integrated circles and from level flights taken subsequently at the same target, do not provide coincident phases, supporting the assumption, that measured signals are still primarily random.

\section{REQUIREMENT FOR NEW CAMPAIGN}

The LOSAC campaign provided us with the knowledge, that if there is an azimuth signal, it is smaller than $100 \mathrm{mK}$ $200 \mathrm{mK}$. It did, however, reveal several new problems for the processing of the satellite data, especially regarding the geophysical noise and the correction for galactic radiation.

The nature of the observed geophysical noise is still unknown, but similar effects have been observed by JPL and NASA/Goddard. For level flights, the wiggles are typically of the order of $1 \mathrm{~K}$ with a scale length of $5-10 \mathrm{~km}$, and they are expected to average out using the much larger foot-print associated with spaceborne instruments, but this remains to be proven. A future experiment can not easily address this problem, as the foot-print size is a direct function of the altitude, and a wider antenna beam will cause other problems with respect to averaging over a wide range of incidence angles. Some compromises must be made, however, and a combination of higher flight altitude, larger antenna beamwidth, and temporal integration can be used.

With respect to a better estimation of the azimuth signal magnitude, the geophysical noise is limiting, and the only way to reduce it is through integration. During LOSAC, integration of up to 16 circles was carried out and a central parameter in the future campaign is a significant increase in the number of circles. This may be reached through extension of the duration of each flight, but as this is often not possible due to aircraft endurance, the only solution is to limit the coverage to one incidence angle, thus using the full time at the target position to perform equal circles. Coverage of several incidence angles is another important issue, however, as the SMOS satellite will range from about $0^{\circ}$ to $60^{\circ}$, but this problem may be solved through parallel data acquisition from several antennas.

Correction for galactic radiation is a serious open issue, as the method applied to the LOSAC data is not directly transferable to the satellite data. LOSAC obviously proved, that correction, based only on the theoretical Fresnel reflection coefficient, is too simple, and at least this coefficient has to be scaled, according to the actual roughness of the sea. The scaling, however, is found from the regression over the full azimuth range, and as only one observation direction is available from the satellite, the scaling coefficient can not be estimated from the data. LOSAC also proved that the scaling coefficient is not a simple function of the meteorological conditions.

The simple scaling has the fundamental problem that it does not account for radiation, scattered in other directions than the direction obtained from geometrical optics. A complete input to the satellite data processor must thus be a scattering function, providing the expected amount of scattered energy as a function of incidence angle, azimuth direction, and surface roughness conditions. The galactic signal contribution is thus given as the convolution of this function with the galactic background map. For an airborne experiment, the major problem is that it is difficult to de-convolute the measured data from the galactic map, and at best it requires a very high number of flights. This problem may be circumvented by replacement of the complex background by a simple deltafunction, i.e. a very strong point target such as the Sun, as the 
convolution with a delta-function is a neutral process. At Lband the Sun is a strong emitter, providing more than $10^{5} \mathrm{~K}$, and any other contributor may thus be neglected. To obtain the scattering function, scanning in azimuth, i.e. circles, and in elevation, i.e. changes of aircraft pitch or roll, must be carried out.

As a final aspect, which was left uncovered by the LOSAC campaign, possible radio frequency interference, RFI, should be investigated in a future campaign. Other L-band campaigns have experienced very different results, and a typical situation could be a radar causing pulse-type disturbances to the radiometer, adding a small bias to the integrated output. The new generation of the EMIRAD radiometer [3] has a digital detector, and it features direct digital output of undetected and un-integrated data. The radiometer was used for measurements over land in Australia in the fall of 2005, and a typical measurement situation is seen in figure 5 , illustrating raw data samples over a period of $25 \mu \mathrm{sec}$. in the upper pane, and zoomed to the possible RFI in the lower pane.
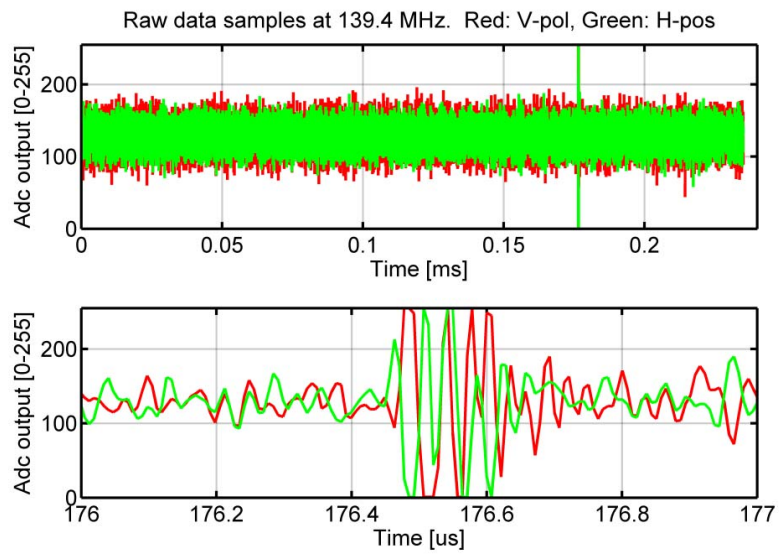

Figure 5. Raw data samples from the EMIRAD radiometer, illustrating possible short RFI pulses in the measured data.

\section{CoSMOS CAMPAign}

A new campaign for mapping of sea surface salinity, known under the acronym CoSMOS, is carried out during April 2006, using the second generation digital detection EMIRAD radiometer, which features fast time-multiplexed data recording from two different antennas. The system is installed in a Skyvan aircraft of Helsinki University of Technology as illustrated in figure 6 , and incidence angles of $0^{\circ}$ and $40^{\circ}$ (aft looking) have been selected. Aircraft attitude is measured with a precision $0.05^{\circ}$ using the Honeywell H-764 embedded GPS/INS, and a nadir looking thermal infrared sensor monitors the sea surface temperature.

For all flights, the time at target has been chosen to coincide with an ENVISAT/ASAR overpass to obtain information about the actual surface roughness, and meteorological information is provided from oil-drilling installations in the target area.

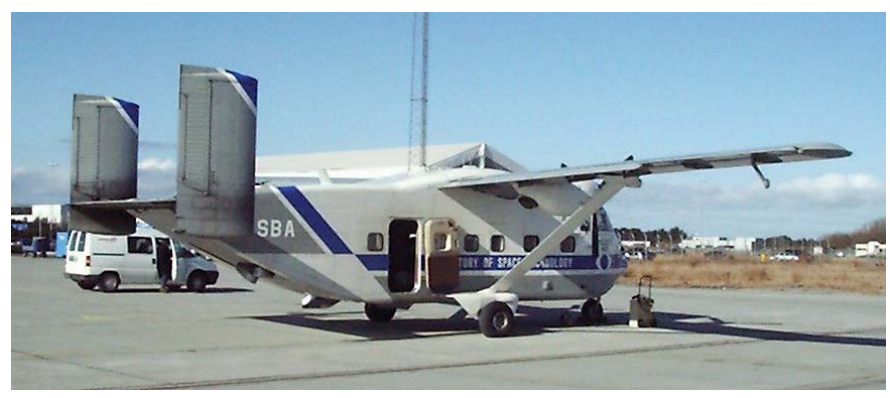

Figure 6. Skyvan with aft and nadir pointing EMIRAD antennas.

The campaign target area is the North Sea, and two different flights types are carried out.

- Circle flights with more than one hour data acquisition over the target area, keeping a constant $15^{\circ}$ bank angle. This flight type is carried out at night, and a total of eight flights are foreseen.

- Sun flights with smooth dives to sample different incidence angles. Flights carried out with antennas pointing to Sun azimuth and away from sun azimuth. Level flight is done perpendicular to the Sun, and azimuth signatures are sampled from circles. The four flights of this type are carried out around noon, with a total duration of more than one hour.

\section{CONCLUSIONS}

A survey of two airborne campaigns for measurement of sea surface salinity has been presented. Major results from the LOSAC campaign are outlined and open issues for satellite measurements are identified. These concentrate on:

- More data in order to reduce geophysical noise.

- Better spatial averaging for understanding of geophysical noise influence on larger pixels.

- Acquisition of bistatic surface scattering function for correction for galactic radiation.

- Possible recording and mitigation of radio frequency interference. Identification of sources.

The CoSMOS campaign with a total of 12 flights during April 2006 aims at these objectives and with parallel access to sea surface temperature and surface roughness data, the campaign is expected to fill the voids. Likewise the duration of the campaign is an important parameter for sampling of different meteorological conditions.

\section{REFERENCES}

[1] J. Rotbøll, S. S. Søbjerg, and N. Skou: "A Novel L-band Polarimetric Radiometer Featuring Subharmonic Sampling", Radio Science, Vol 38, No. 3, May-June 2003, pp 11-1-11-7.

[2] S. S. Søbjærg, J. Rotbøll, and N. Skou: "The L-band Ocean Salinity Airborne Campaign, LOSAC ", Ørsted-DTU, Final Report, May 2004, $163 p$.

[3] N. Skou, S. S. Søbjærg, J. Balling, and S. S. Kristensen: "A Second Generation L-band Digital Radiometer for Sea Salinity Campaigns", Proceedings of IGARSS'06, august 2006, 4 p. 